\title{
ANALYTICA
}

CHIMICA

ACTA

ELSEVIER

Analytica Chimica Acta 434 (2001) 291-300

www.elsevier.com/locate/aca

\section{Determination of mercury in process and lagoon waters by inductively coupled plasma-mass spectrometric analysis after electrochemical preconcentration: comparison with anodic stripping at gold and polymer coated electrodes}

\author{
Paolo Ugo ${ }^{\mathrm{a}, *}$, Silvana Zampieri ${ }^{\mathrm{a}}$, Ligia Maria Moretto ${ }^{\mathrm{a}}$, Daniele Paolucci ${ }^{\mathrm{b}}$ \\ a Department of Physical Chemistry, S. Marta 2137, Chemical Analysis Laboratory, Via Torino-Mestre, \\ Università Cà Foscari di Venezia, I-30123 Venezia, Italy \\ ${ }^{\mathrm{b}}$ EniChem Research Centre, Via della Chimica 5, I-30175 Porto Marghera, Venice, Italy
}

Received 4 August 2000; received in revised form 5 December 2000; accepted 19 January 2001

\begin{abstract}
A combined electrochemical-inductively coupled plasma-mass spectrometry (EC-ICP-MS) method for the determination of trace mercury in water samples is presented. It takes advantage of the electrochemical preconcentration of mercury onto a gold spiral electrode followed by ICP-MS analysis after the electrochemical reoxidation of deposited mercury in pure supporting electrolyte. The advantages of the EC-ICP-MS approach with respect to conventional ICP-MS, are the increased sensitivity and the elimination of the effect of interfering substances eventually present in the sample.

EC-ICP-MS is applied to the determination of nanomolar and subnanomolar concentrations of mercury(II) ions in real samples such as process waters (from a chlor-alkali plant) and lagoon waters (from Venice channels). Analytical performances obtained by EC-ICP-MS are discussed and compared with those obtained by anodic stripping voltammetry at gold and at Tosflex-coated glassy carbon electrodes. () 2001 Elsevier Science B.V. All rights reserved.
\end{abstract}

Keywords: Mercury; Electrochemical preconcentration; ICP-MS; Process water; Venice lagoon

\section{Introduction}

Anodic stripping voltammetric methods for the determination of trace mercury have been introduced successfully some years ago [1-3]. The best electrodic material to this aim is gold, which allows the efficient Faradaic preconcentration of metallic mercury as an amalgam. Sensitive methods have been developed also by using chronopotentiometric stripping on the same

\footnotetext{
* Corresponding author. Tel.: +39-041-2578503; fax:+39-041-2578594.

E-mail address: ugo@unive.it (P. Ugo).
}

electrode material [4-7]. In spite of the high sensitivity and relatively short preconcentration time, the use of gold electrodes suffers for some limitations, particularly for analysis in chloride containing samples; in fact, during the anodic stripping scan, gold itself can be oxidised to give soluble $\mathrm{Au}$ (III) chloride complexes [2]. Moreover, the interference coming from copper can be quite heavy. In real samples copper is usually present in large excess with respect to $\mathrm{Hg}$ and is codeposited with mercury. These drawbacks can be overcome by resorting to medium exchange and/or by using unconventional electrode configurations [2]. 
More recently, modified electrodes have been applied to trace mercury analysis; they take advantage of the preconcentration ability of the modifiers which can incorporate the analyte via ion-exchange [8-11] or via complexation reactions [12-14]. Among the others, the use of glassy carbon electrodes modified with the perfluorinated anion-exchanger Tosflex IE-SA 48 [8] appeared particularly suitable for practical purposes. The application of the Tosflex coating is achieved by simple solvent evaporation of deposited microvolume of polymer solution; moreover, the modified electrodes are stable and the determination of mercury at trace levels can be performed with very good rejection of the copper interference thanks to the different ionic charges of $\mathrm{Hg}$ (II) and $\mathrm{Cu}$ (II) complexes in chloride containing media $[8,15]$.

Recently, for determinations in complex matrices, electrochemical preconcentration has been introduced also as an auxiliary tool for spectroscopic analysis $[16,17]$ giving rise to electrochemical-inductively coupled plasma-mass spectrometry (EC-ICP-MS) methods. In the case of mercury analysis, ICP-MS can be used for the direct determination of mercury at trace levels $[18,19]$. However, in addition to problems related to the relatively low ionisation efficiency which characterises the ICP-MS determination of this element [20], ICP-MS analyses in matrices with high salts contents, such as seawaters, suffer for the formation of salt deposits on the small orifices which constitute the interface between the plasma torch and the mass analyser. These problems can be solved by performing the electrochemical deposition of mercury followed by stripping after transfer in a "clean" solution which is then sent to the ICP-MS instruments. The EC-ICP-MS approach has been used for a variety of analytes such as for instance Cr and V [21], As and $\mathrm{Se}$ [22], $\mathrm{Cu}$ and $\mathrm{Cd}$ [23], while for mercury only one example has been reported in the literature [24]. The method proposed in ref. [24] consisted of the electrodeposition of mercury, together with other trace metals, on a niobium electrode followed by a time consuming $(2 \mathrm{~h})$ chemical stripping step in concentrated nitric acid solution and subsequent dilution.

With the goal of developing a faster method specifically suitable for mercury trace determinations in complex samples, in the present paper we examine the use of gold spiral electrodes and the adoption of an electrochemical reoxidation procedure coupled to the ICP-MS analyses.

The EC-ICP-MS method is applied to mercury analysis in process waters (from a chlor-alkali plant) and in lagoon waters (from Venice channels). Analytical performances offered by EC-ICP-MS are compared with those obtained by anodic stripping voltammetry at gold electrodes or at Tosflex-coated glassy carbon electrodes.

\section{Experimental}

\subsection{Chemicals}

All chemicals used were of analytical reagent grade or higher $\left(\mathrm{HNO}_{3}, \mathrm{HCl}, \mathrm{NaCl}\right.$ Suprapur ${ }^{\circledR}$ from Merck). Milli-Q water was used throughout for preparing supporting electrolyte solutions. $\mathrm{Hg}$ (II) solutions were prepared by proper dilution of mercury standard solution $(1000 \mathrm{mg} / \mathrm{l}$, Aldrich). Aqueous alcoholic solutions (water + methanol +2 -propanol, 1:1:1) of Tosflex ${ }^{\circledR}$ IE-SA 48 were prepared from the thick solid membrane using the method of Dunsch et al. [25]. The filtered solution had a concentration of about $2.5 \%(\mathrm{w} / \mathrm{v})$.

\subsection{Apparatus and procedures}

All electroanalytical measurements were carried out at room temperature $\left(22 \pm 1^{\circ} \mathrm{C}\right)$ under a nitrogen or helium atmosphere. Voltammetric measurements were performed by using a conventional single-compartment cell equipped with a $\mathrm{Pt}$ coil or a $\mathrm{Pt}$ net counter electrode and an $\mathrm{Ag} / \mathrm{AgCl}$ reference electrode. In the electrochemical cell used for the electrochemical preconcentration before ICP-MS analysis, the compartment of the working electrode (a gold coil) was separated from the compartment containing the counter electrode (platinum net) by a sintered glass frit.

Gold "macro" electrodes for performing electrochemical preconcentrations were made of coils of gold wire of $0.5 \mathrm{~mm}$ thickness; estimated electrodes areas were 4.7 or $15.7 \mathrm{~cm}^{2}$, depending on the coil length. These electrodes were pre-conditioned by using a procedure similar to the one suggested by Jagner et al. [4]. In particular, the electrodes were cleaned by anodic oxidation at $0.8 \mathrm{~V}$ for $2 \mathrm{~min}$ in diluted nitric acid 
solutions. After oxidation, few pre-electrolysis/stripping cycles were conducted in solutions containing $10^{-7} \mathrm{M}$ mercury(II), until stable ICP-MS mercury readings were obtained. The preconditioned electrodes were used for approximately one week of measurements, before repeating the procedure.

The voltammetric working electrodes were a PTFE-shrouded glassy carbon disk $\left(\right.$ area $0.2 \mathrm{~cm}^{2}$ ) or a gold disk electrodes (area 0.125 or $0.0314 \mathrm{~cm}^{2}$ ), both polished to a mirror finish with graded alumina powder.

Tosflex-coated electrodes were prepared by droplet evaporation of $3 \mu \mathrm{l}$ of $2.5 \%$ (w/v) Tosflex solution, deposited with microsyringe on a mirror-polished glassy carbon disk electrode. The evaporation of the solvent was performed in a methanol atmosphere to ensure a slow evaporation rate [8].

Differential pulse anodic stripping (DPASV) measurements were carried out with an EG\&G PAR mod. 384B apparatus.

For cold vapour atomic absorption-mercury flow injection spectroscopy (CVAAS-FIMS) a Perkin Elmer FIMS 100 System was used. An Elan 5000 instrument (Perkin-Elmer SCIEX, Thornhill, Ont., Canada) was used for ICP-MS analyses. The ICP-MS conditions were selected, in graphic mode, to obtain ion signals higher or equal to $7500,45000,7500 \mathrm{cps}$, respectively for ${ }^{103} \mathrm{Rh},{ }^{24} \mathrm{Mg}$, and ${ }^{207} \mathrm{~Pb}$, while a standard solution of 11 isotopes, which covered the mass range, containing $10 \mathrm{ppb}$ of $\mathrm{Rh}, \mathrm{Mg}$ and $\mathrm{Pb}$, was continuously introduced. The ICP-MS operating conditions used throughout this work are summarised in Table 1.

Table 1

Operating conditions used for ICP-MS measurements

\begin{tabular}{ll}
\hline $\begin{array}{l}\text { Radiofrequency power } \\
\text { Gas flows }\end{array}$ & $1 \mathrm{~kW}$ \\
$\quad$ Coolant & $141 / \mathrm{min}$ \\
Auxiliary & $0.851 / \mathrm{min}$ \\
$\quad$ Nebuliser & $1.11 / \mathrm{min}$ \\
Sample flow rate & $1 \mathrm{ml} / \mathrm{min}$ \\
$\mathrm{m} / z$ & 199,202 \\
Resolution & Normal \\
Points per spectral peak & 1 \\
Number of replicates & 3 \\
Sweeps per reading & 65 \\
Dwell time & $80 \mathrm{~ms}$ \\
Mode & Peak hopping \\
\hline
\end{tabular}

\subsection{Real samples}

Sampling glass bottles, electrochemical cells and all the labware were acid cleaned and conditioned according to usual recommended procedures [26].

Water samples from a chlor-alkali industrial plant which employs mercury cathodes were taken at different points inside the battery limits of the plant (carbon filter, sand filter or water filter), placed downstream of a water treatment section and collected in preconditioned glass bottles. When required, $\mathrm{H}_{2} \mathrm{SO}_{4} 1: 1$ and $\mathrm{KMnO}_{4} 5 \%(\mathrm{w} / \mathrm{v})$ were added to the samples which were incubated in a thermostatic bath at $95^{\circ} \mathrm{C}$ for $30 \mathrm{~min}$ in order to fulfil the oxidation of organic substances eventually present in the sample. The oxidant excess was neutralised with $\mathrm{NH}_{2} \mathrm{OH} \cdot \mathrm{HCl} 5 \%(\mathrm{w} / \mathrm{v})$.

"Synthetic" blanks of process waters were prepared on the basis of the known chemical composition of this kind of samples. In particular, they contained $0.5 \mathrm{M} \mathrm{NaCl}, 0.001 \mathrm{M} \mathrm{Na}_{2} \mathrm{CO}_{3}, 0.003 \mathrm{M} \mathrm{Na}_{2} \mathrm{SO}_{4}$, $0.0085 \mathrm{M} \mathrm{NaOH}, 2.5 \times 10^{-4} \mathrm{M}$ thiourea. These blanks were treated with $\mathrm{H}_{2} \mathrm{SO}_{4} 1: 1, \mathrm{KMnO}_{4} 5 \%$, and $\mathrm{NH}_{2} \mathrm{OH} \cdot \mathrm{HCl} 5 \%$.

Channel waters were sampled in Rio Tentor (Venice) in October 1999, under decreasing tide conditions, with a 201 polypropylene container (preconditioned with channel water), operating from a wood bridge suspended over the channel. After filtration through $0.45 \mu \mathrm{m}$ Millex-HV Millipore membrane, $2 \mathrm{ml} / \mathrm{l}$ of Suprapur hydrochloric acid (30\% w/w) were added to the sample.

All measurements in real samples were performed in a clean laboratory of the EniChem Research Centre (Porto Marghera) where no mercury was manipulated and polarographs have never been used; this in order to avoid any possible mercury contamination from the laboratory environment.

\section{Results and discussion}

\subsection{Synthetic samples}

As mentioned in the Section 1, the adoption of an electrochemical preconcentration step coupled to an ICP-MS detection method, in principle, can eliminate some of the main drawbacks found in the ICP-MS determination of mercury in real samples. A prerequisite which should drive the choice of the electrode used for 
the preconcentration is that it should be a large area electrode (see below) which allows the quick and (possibly) complete stripping of preconcentrated mercury in small volume stripping solutions. Electrodes usually employed to this aim have complex shapes such as nets, spirals or porous solids. Unfortunately, this kind of electrodes is not the best choice for performing the reproducible and uniform deposition of Tosflex [8] or of other mercury preconcentrating materials [9-12]. For this reason, we started the development of EC-ICP-MS methods for mercury analyses by using simply unmodified gold electrodes. In order to choose the best experimental conditions, some aspects of the electrochemistry of mercury on gold which are relevant to the optimisation of the EC-ICP-MS procedure, has been shortly revisited.

Fig. 1 shows the effect of the faradaic preconcentration time on the DPASV patterns recorded at a gold electrode in a $10^{-7} \mathrm{M} \mathrm{Hg}^{2+}$ solution, after deposition at $0.1 \mathrm{~V}$. When the deposition time is increased from $60 \mathrm{~s}$ (solid line) to 300 (dashed line), 900 (dotted line) or $1200 \mathrm{~s}$ (dashed-dotted line), the voltammetric patterns show progressively more complicated features. For a deposition time shorter than $5 \mathrm{~min}$, only peak 4 is detected, which corresponds to the peak expected for the stripping of a mercury monolayer [27,28]. Peaks
1-3 appear and grow progressively when the preconcentration time is increased. They are related to the oxidation of massive phases of mercury deposited on gold and to the formation of $\mathrm{Hg}-\mathrm{Au}$ intermetallic compounds [3]. Note that similar complications are observed when using short preconcentration time in more concentrated solutions (e.g. $60 \mathrm{~s}$ in $10^{-6} \mathrm{M} \mathrm{Hg}^{2+}$ ).

As shown by the inset in Fig. 1, the appearance of various peaks reflects in calibration curves which are linear only over relatively short concentration ranges. The sensitivity (slope of the calibration plot) is higher for $\mathrm{Hg}$ (II) concentrations lower than $10^{-8} \mathrm{M}$, while it decreases in more concentrated solutions. In any case, linear plots extended over relatively short concentration ranges can be individuated.

These problems can be overcome by determining the amount of mercury deposited via a detection method such as ICP-MS which gives an integral response, independently on the nature (amalgam, monolayer, intermetallics etc.) of the deposited phase(s).

In order to study the feasibility of the EC-ICP-MS approach, the following procedure was adopted:

- potentiostatic electrochemical deposition of mercury from the acidified sample solution on a gold coil electrode, $E_{\text {appl }}=-0.1 \mathrm{~V}$ versus $\mathrm{Ag} / \mathrm{AgCl}$;

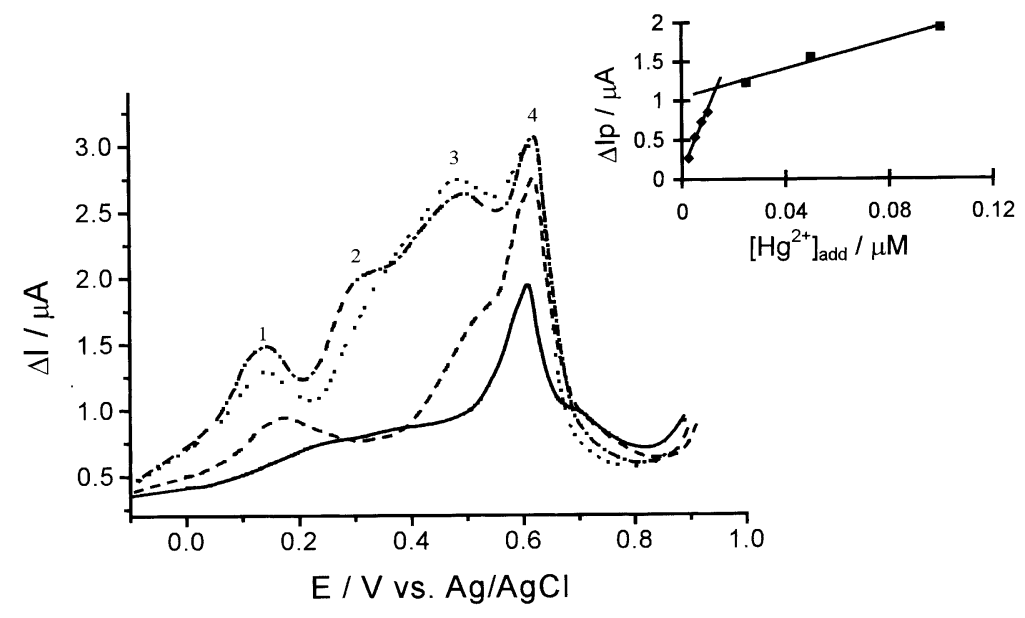

Fig. 1. Differential pulse stripping voltammograms of $10^{-7} \mathrm{M} \mathrm{Hg}^{2+}, 0.1 \mathrm{M} \mathrm{NaNO} 32.5 \times 10^{-3} \mathrm{M} \mathrm{HCl}$, at a gold disk electrode. Preconcentration carried out while rotating the electrode at $2000 \mathrm{rpm}$, at $-0.1 \mathrm{~V}$ for $60 \mathrm{~s}$ (full line), $300 \mathrm{~s}$ (dashed line), $900 \mathrm{~s}$ (dotted line) and $1200 \mathrm{~s}$ (dashed-dotted line); stripping at $0 \mathrm{rpm}$. DPASV scan parameters: pulse height $50 \mathrm{mV}$; step time $0.2 \mathrm{~s}$; scan increment $2 \mathrm{mV}$; scan rate $10 \mathrm{mV} / \mathrm{s}$. Inset: calibration plot obtained by plotting the differential peak current recorded at $0.6 \mathrm{~V}$ (peak 4) after preconcentration at $-0.1 \mathrm{~V}, 2000 \mathrm{rpm}$, for $300 \mathrm{~s}$. 
- transfer of the electrode to another cell which contains lower quantity of pure diluted acid;

- reoxidation of the mercury deposit by using a constant oxidation potential $\left(E_{\mathrm{appl}}=0.8 \mathrm{~V}\right.$ versus $\mathrm{Ag} / \mathrm{AgCl}$ ) for $15 \mathrm{~min}$;

- ICP-MS analysis of the collected solutions.

Note that the reoxidation potential was chosen on the basis of the DPASV results which showed that full reoxidation of mercury is achieved under the conditions listed above.

The efficiency of the preconcentration step can be quantified by a preconcentration factor (PF) defined by Eq. (1):

$\mathrm{PF}=\frac{[\mathrm{Hg}]_{\mathrm{f}}}{[\mathrm{Hg}]_{0}}$

where $[\mathrm{Hg}]_{\mathrm{f}}$ is the concentration determined by ICP-MS after electrochemical preconcentration and $[\mathrm{Hg}]_{0}$ is the mercury concentration in the sample.

PF depends on various parameters. First of all, it is related to the ratio between the volume of the reduction solution and the reoxidation solution. This ratio corresponds to the theoretical value of PF that would be obtained if all the mercury in solution would be deposited quantitatively on the gold coil and totally stripped during the reoxidation. Fig. 2 shows that keeping the ratio between the solutions volumes constant, the preconcentration factor increases with the deposition time, reaching a value of 5.5 (which is rather close to the theoretical value of 6.7 ) after $60 \mathrm{~min}$ preconcentration.

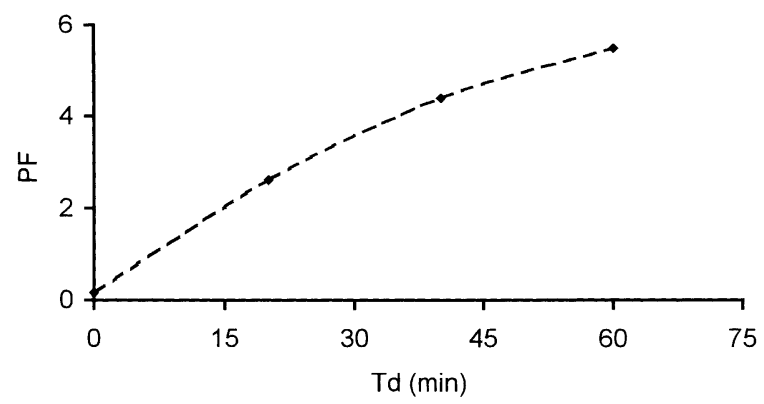

Fig. 2. Effect of the deposition time on the preconcentration factor $\mathrm{PF}=[\mathrm{Hg}]_{\mathrm{f}} /[\mathrm{Hg}]_{0}$, where $[\mathrm{Hg}]_{\mathrm{f}}$ is the concentration determined by ICP-MS after electrochemical preconcentration and $[\mathrm{Hg}]_{0}$ is the mercury concentration in the sample. Deposition at $-0.1 \mathrm{~V}$ at a spiral gold electrode $\left(4.7 \mathrm{~cm}^{2}\right)$ in $40 \mathrm{ml}$ of $0.5 \mathrm{M} \mathrm{NaCl}, 10^{-2} \mathrm{M}$ $\mathrm{HCl}$ containing $10^{-8} \mathrm{M} \mathrm{Hg}^{2+}$. Stripping in $6 \mathrm{ml}$ of $10^{-2} \mathrm{M} \mathrm{HCl}$.
Table 2

Preconcentration factors obtained using different supporting electrolytes for the electrochemical preconcentration step

\begin{tabular}{|c|c|c|}
\hline Supporting electrolyte & $\begin{array}{l}\text { Conductivity } \\
(\mathrm{mS} / \mathrm{cm})\end{array}$ & $\begin{array}{l}\text { Preconcentration } \\
\text { factor }\end{array}$ \\
\hline $0.1 \mathrm{M} \mathrm{NaNO}_{3}+10^{-2} \mathrm{M} \mathrm{HCl}$ & 13.6 & 1.3 \\
\hline $0.1 \mathrm{M} \mathrm{HCl}$ & 34.8 & 1.67 \\
\hline $0.5 \mathrm{M} \mathrm{NaCl}+10^{-2} \mathrm{M} \mathrm{HCl}$ & 44.5 & 2.1 \\
\hline
\end{tabular}

Measurements carried out using different kinds and different concentrations of supporting electrolytes for the preconcentration step, show that PF increases with the electrolyte conductivity (see Table 2).

In order to avoid problems during the ICP-MS detection, the concentration of the electrolyte used in the reoxidation step must be relatively low; diluted solutions of strong acid were chosen since they assure high conductivities without giving any salt deposits at the ICP-MS interface (sampler cone orifice).

At short preconcentration time, the value of the preconcentration factor is ruled by the geometric area of the working electrode; for instance, a gold coil of $15.7 \mathrm{~cm}^{2}$ area gives a preconcentration factor of 6.86 , when using a solution volumes ratio of 13.3 and $20 \mathrm{~min}$ deposition time, while a smaller electrode $\left(4.71 \mathrm{~cm}^{2}\right.$ area) in the same conditions gives a preconcentration factor of only 4.2.

Linear calibration plots are obtained under the following experimental conditions:

- preconcentration at a spiral gold electrode $\left(15.7 \mathrm{~cm}^{2}\right)$ in $40 \mathrm{ml}$ of $0.5 \mathrm{M} \mathrm{NaCl}, 10^{-2} \mathrm{M} \mathrm{HCl}$;

- stripping in $3 \mathrm{ml}$ of $10^{-2} \mathrm{M} \mathrm{HCl}$.

Table 3 compares sensitivities and standard deviations of blanks $\sigma_{0}$ measured by ICP-MS and

Table 3

Comparison of statistical data obtained for trace levels mercury determinations using ICP-MS with and without electrochemical preconcentration

\begin{tabular}{lll}
\hline & Sensitivity $(\mathrm{cps} / \mu \mathrm{M})$ & $\sigma_{0}(\mathrm{ion} / \mathrm{s})$ \\
\hline EC-ICP-MS $^{\mathrm{a}}$ & $1.4 \times 10^{6}$ & $50^{\mathrm{b}}$ \\
ICP-MS $^{\mathrm{b}}$ & $2.1 \times 10^{5}$ & $4^{\mathrm{c}}$ \\
\hline
\end{tabular}

${ }^{\mathrm{a}}$ Electrochemical deposition at gold spiral electrode $\left(15.7 \mathrm{~cm}^{2}\right)$ for $20 \mathrm{~min}$ at $-0.1 \mathrm{~V}$. Stripping in $10^{-2} \mathrm{M} \mathrm{HCl}(3 \mathrm{ml})$ at $0.8 \mathrm{~V}$ for $15 \mathrm{~min}$ followed the ICP-MS analysis.

${ }^{\mathrm{b}}$ Calculated from 5 independent measurements.

${ }^{\mathrm{c}}$ Calculated from 10 independent measurements. 
by EC-ICP-MS in synthetic samples. The sensitivity increases significantly when the electrochemical preconcentration step is used, however, the blank standard deviation increases as well, because of the not perfect reproducibility of this step. This indicates that EC-ICP-MS is particularly advantageous for eliminating matrix effects in samples containing high concentrations of substances which can interfere with the ICP-MS analysis in crude samples. On the other hand, the increase in background noise is the fee that one has to pay when using an heterogeneous preconcentration step which can bring reproducibility problems related to memory effects of electrode surfaces.

\subsection{Process waters}

The EC-ICP-MS method above described has been tested and compared with other methods used for the analysis of trace mercury in industrial and environmental samples. At first, samples taken from a mercury exhaustion section for chlor-alkali process waters were examined. In this plant, the concentration of mercury in the waters is lowered via a treatment with thiourea, carried out in an alkaline environment [29]; under these conditions mercury precipitates as $\mathrm{HgS}$. The decontaminated solution is then separated from the sediment by a flocculation process.

Problems related to the use of electrochemical methods for preconcentrating mercury in this kind of samples were examined at first by DPASV at gold electrodes. Fig. 3a, dashed line, shows the differential pulse stripping voltammogram recorded at a gold disc electrode dipped in a water sample from this plant, after the addition of nitric acid. The mercury stripping peak is almost undetectable. Results presented in Fig. $3 b$ (relevant to a synthetic sample) indicate that thiourea is responsible for the disappearance of the mercury peak. In fact, while in a synthetic sample, containing $5 \times 10^{-8} \mathrm{M}$ copper and $10^{-8} \mathrm{M}$ mercury, but no thiourea, two separated stripping peaks are detected (full line in Fig. 3b), the addition to the same sample of $2.5 \times 10^{-4} \mathrm{M}$ thiourea causes the almost complete disappearance of the mercury peak (dashed line in Fig. 3b). This agrees with mercury(II) complexation by thiourea [30], which hinders the electrochemical reduction and preconcentration of mercury as a metal phase detectable with the stripping step.
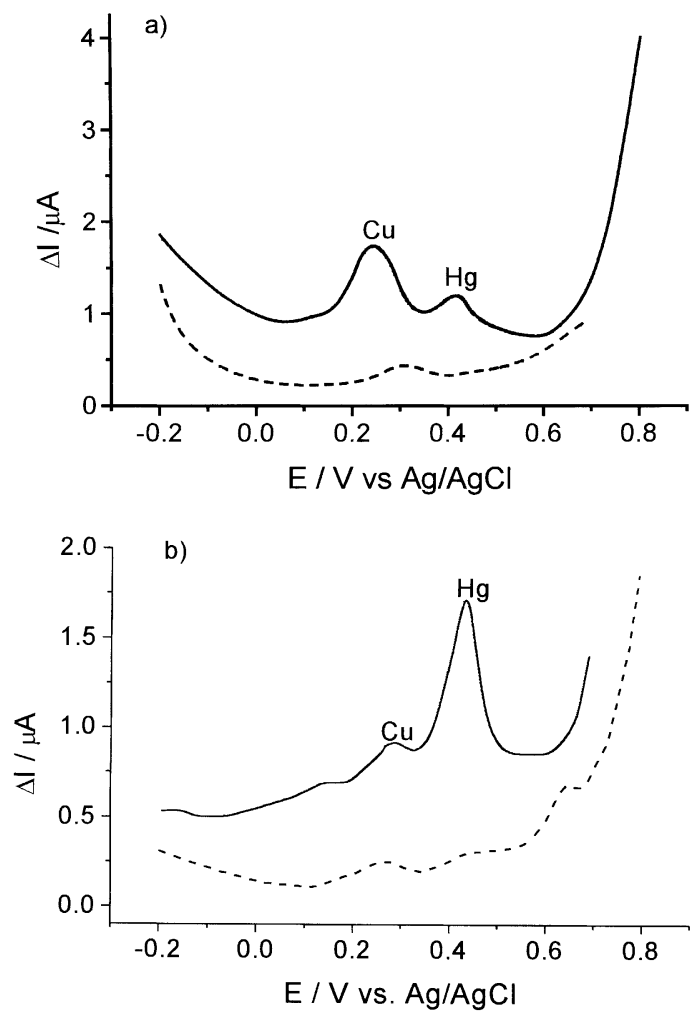

Fig. 3. Differential pulse anodic stripping voltammograms recorded at a gold disk electrode, recorded after deposition at $-0.2 \mathrm{~V}$ for $600 \mathrm{~s}$ in: (a) a chlor-alkali water sample acidified with $\mathrm{HNO}_{3}$ $(\mathrm{pH}=2.5)$ (dashed line) and after treatment with $\mathrm{KMnO}_{4}$ (full line); (b) a synthetic sample containing $10^{-8} \mathrm{M} \mathrm{Hg}^{2+}, 5 \times 10^{-8} \mathrm{M}$ $\mathrm{Cu}^{2+}, 0.5 \mathrm{M} \mathrm{NaCl}, 10^{-2} \mathrm{M} \mathrm{HCl}$ (full line) and after the addition of $2.5 \times 10^{-4} \mathrm{M}$ thiourea (dashed line). Other experimental conditions as in Fig. 1.

By treating the process waters with $\mathrm{KMnO}_{4}$, which oxidises thiourea, the voltammogram shown in Fig. 3a (full line) is obtained. In these conditions, the mercury reoxidation peak at about $420 \mathrm{mV}$ re-appears. The $\mathrm{Hg}$ peak is accompanied by (but well resolved from) the $\mathrm{Cu}$ peak. Note that in the examined sample the copper concentration (determined by ICP-MS) is $5.7 \times 10^{-7} \mathrm{M}$. By using the pretreatment, the peak relevant to the reoxidation of $\mathrm{Hg}$ increases linearly with mercury concentration and quantitative analysis can be performed by the standard additions method.

Fig. 4 shows the voltammogram recorded at a Tosflex-coated glassy carbon electrode (TCE) in the sample treated with $\mathrm{KMnO}_{4}$. The measurement was 


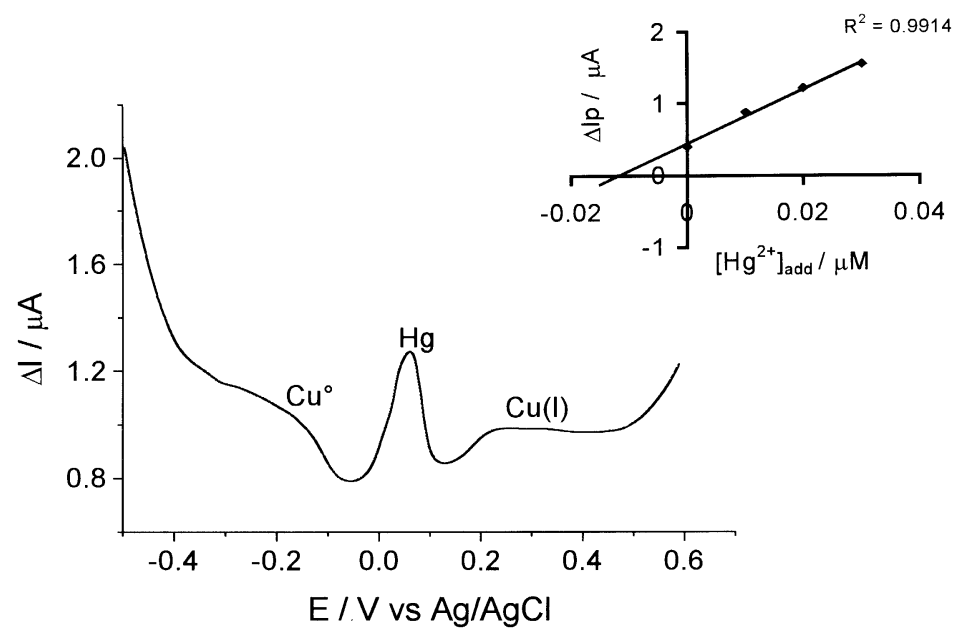

Fig. 4. Differential pulse stripping voltammogram recorded at a Tosflex-coated glassy carbon electrode in a chlor-alkali water sample treated with $\mathrm{KMnO}_{4}$. Open circuit ion-exchange preconcentration for $900 \mathrm{~s}$ followed by reduction at $-0.5 \mathrm{~V}$ for $600 \mathrm{~s}$. DPASV parameters: pulse height $25 \mathrm{mV}$; step time $0.5 \mathrm{~s}$; scan increment $5 \mathrm{mV}$; scan rate $10 \mathrm{mV} / \mathrm{s}$. Inset: standard addition plot.

carried out after open circuit ion-exchange preconcentration for $15 \mathrm{~min}$, followed by reduction at $-0.5 \mathrm{~V}$ for $10 \mathrm{~min}$. Note that a mercury reduction potential more negative then the one adopted previously for measurements in sea and lagoon waters [8] was used here. This allows one to achieve a higher sensitivity for mercury determination, while keeping the effect of copper interference at acceptable levels. As shown in Fig. 4, at the TCE the mercury peak is still the prevailing one even if $\mathrm{Cu}$ is present in excess. Under the experimental conditions here adopted, copper is reduced to the metal phase and not to $\mathrm{CuCl}_{2}{ }^{-}$which is the main copper reduction product produced when the reduction is carried out at $-0.25 \mathrm{~V}[8,15]$. However, even if $\mathrm{Cu}^{2+}$ is in excess with respect to $\mathrm{Hg}^{2+}$, the $\mathrm{Cu}^{0}$ and $\mathrm{Cu}(\mathrm{I})$ reoxidation peaks result very small. The prevailing $\mathrm{Cu}$ (II) species are, indeed, the cations $\mathrm{Cu}^{2+}$ and $\mathrm{CuCl}^{+}[15,31]$ which are rejected from the polycationic Tosflex coating. Also in this case mercury concentrations can be obtained by standard additions.

Mercury determinations by ICP-MS without electrochemical preconcentration did not give reliable results in this kind of samples, even after the $\mathrm{KMnO}_{4}$ treatment. Note that these samples require a 100 -fold dilution with water to lower the overall salts content below $0.2 \%$. On the contrary, satisfactory results are achieved by applying the EC-ICP-MS method. The preconcentration factor, PF calculated from linear standard additions plots, is approximately equal to 4 , which is only slightly smaller than the value of 6.86 , obtained for analysis of synthetic samples under the same experimental conditions.

Standard deviations of blank solutions were obtained by analysing synthetic blanks with a chemical composition (see Section 2) as close as possible to the one expected for process waters (but with no mercury). Blank standard deviations, detection and quantification limits are listed in Table 4.

This table compares the concentrations of mercury determined in process water samples by DPASV and EC-ICP-MS as well as by FIMS-CVAAS, used as a reference method. The mercury concentrations determined with the different methods are in satisfactory agreement. Detection limits relevant to DPASV at Au and TCE electrodes are comparable each other. Note that DPASV detection limits in process samples are about 5-6 times higher than those reported in the literature for "cleaner" samples [2,6-8]. As above discussed, this is a consequence of the interference effect caused by thiourea; such problems are eliminated by the permanganate treatment whose adoption, however, causes an increase of the background noise $\left(\sigma_{b}\right)$. A pleasing result is that, in the examined process 
Table 4

Mercury concentrations and statistical data obtained for the analysis of a chlor-alkali water sample by using different analytical methods

\begin{tabular}{|c|c|c|c|c|}
\hline & DPASV-Au & DPASV-TCE & EC-ICP-MS & FIMS-CVAAS \\
\hline $\begin{array}{l}\text { Found } \pm \text { S.D. } \\
\sigma_{0} \\
\mathrm{DL}^{\mathrm{e}}\end{array}$ & $\begin{array}{l}(9 \pm 0.5) \times 10^{-9} \mathrm{M} \\
0.004 \mu \mathrm{A}^{\mathrm{a}} \\
3.35 \times 10^{-10} \mathrm{M}\end{array}$ & $\begin{array}{l}(9.5 \pm 1) \times 10^{-9} \mathrm{M} \\
0.005 \mu \mathrm{A}^{\mathrm{b}} \\
3.95 \times 10^{-10} \mathrm{M}\end{array}$ & $\begin{array}{l}(8 \pm 0.25) \times 10^{-9} \mathrm{M} \\
38.5 \mathrm{ion} / \mathrm{s}^{\mathrm{c}} \\
1.5 \times 10^{-10} \mathrm{M}\end{array}$ & $\begin{array}{l}(7.5 \pm 0.1) \times 10^{-9} \mathrm{M} \\
8 \times 10^{-5} \mathrm{abs}^{\mathrm{d}} \\
0.9 \times 10^{-10} \mathrm{M}\end{array}$ \\
\hline
\end{tabular}

a Calculated from six independent measurements.

${ }^{\mathrm{b}}$ Calculated from six independent background determinations carried out at freshly prepared modified electrodes.

${ }^{\mathrm{c}}$ Calculated from five independent measurements. Experimental conditions as in Table 3.

${ }^{\mathrm{d}}$ Calculated from five independent measurements.

${ }^{\text {e }}$ Calculated as $3 \sigma_{0} / m$, where $m$ : sensitivity.

waters, the DL achieved by EC-ICP-MS is even lower than the one obtained by DPASV. Considering that, for the process waters here examined, ICP-MS alone does not give reliable results, the EC-ICP-MS procedure confirms its suitability for the analysis.

\subsection{Lagoon waters}

The methods above described have been applied to the determination of mercury in water samples of a Venice channel.

The filtered sample, acidified to $\mathrm{pH} 2$ with Suprapur ${ }^{\circledR} \mathrm{HCl}$, was analysed at first by DPASV at a gold electrode. On the basis of an expected mercury concentration lower than $5 \times 10^{-10} \mathrm{M}[12]$, a faradic preconcentration time of 20 min was adopted.

Determination with TCEs were performed by using $15 \mathrm{~min}$ ion-exchange preconcentration followed by electrochemical reduction for $10 \mathrm{~min}$ at $-0.2 \mathrm{~V}$ and DPASV anodic detection of preconcentrated mercury.

In channel water samples the mercury reoxidation peak potential was $500 \mathrm{mV}$ on gold and $70 \mathrm{mV}$ at the TCE. At both electrodes, peak currents increased with standard additions of mercury and the mercury concentrations determined are reported in the first two lines of Table 5.

Signals obtained by applying the EC-ICP-MS method to these samples increased only with standard addition of mercury higher than $1.5 \times 10^{-9} \mathrm{M}$. In any case, graphical extrapolation of the linear portion of the standard additions plot gave a mercury concentration in the sample of $(3.7 \pm 1.8) \times 10^{-10} \mathrm{M}$ (see third line in Table 5). The large standard deviation of these data indicates that the concentration determined is very close to the detection limit of the EC-ICP-MS method.

Note that problems in this kind of sample are related more to the low levels of mercury to be determined rather than to the complexity of the matrix. Apart the large uncertainty for the EC-ICP-MS analysis, values determined with the different techniques are in satisfactory agreement each other and with FIMS-CVAAS (see Table 5). Such an agreement confirms somehow the accuracy of the studied methods; note that, in this case, accuracy cannot be verified by analysing seawater samples containing certified mercury concentrations. In fact, it is difficult to define ideal physico-chemical conditions for storing

Table 5

Mercury concentrations in channel waters of the lagoon of Venice

\begin{tabular}{lllll}
\hline Method & Sampling location & Sampling date & {$[\mathrm{Hg}](\mathrm{M})$} & Reference \\
\hline DPASV-Au & Rio Tentor (Venice) & $10 / 99$ & $(3.8 \pm 0.7) \times 10^{-10}$ & Present work \\
DPASV-TCE & Rio Tentor (Venice) & $10 / 99$ & $(3.9 \pm 1) \times 10^{-10}$ & Present work \\
EC-ICP-MS & Rio Tentor (Venice) & $10 / 99$ & $(3.7 \pm 1.8) \times 10^{-10}$ & Present work \\
FIMS-CVAAS & Rio Tentor (Venice) & $10 / 99$ & $(4.0 \pm 0.3) \times 10^{-10}$ & Present work \\
SMSPE $^{\mathrm{a}}$ & Canal Grande (Venice) & $10 / 97$ & $(0.3 \pm 0.05) \times 10^{-10}$ & {$[12]$} \\
SMSPE $^{\mathrm{a}}$ & Rio Arzere (Venice) & $10 / 97$ & $(6 \pm 0.2) \times 10^{-10}$ & {$[12]$} \\
DPASV-TCE & S. Marco Basin (Venice) & $7 / 94$ & $(4.2 \pm 1.2) \times 10^{-10}$ & {$[8]$} \\
\hline
\end{tabular}

${ }^{\text {a }}$ SMSPE: screen printed electrode modified with sumichelate Q $10 \mathrm{R}$ (a dithiocarbamate based chelating resin). 
seawater samples containing so low mercury concentrations [32].

The last three lines of the Table 5 summarise data achieved in previous works by some of the authors of the present paper. They were obtained by using different electrochemical methods and refer to Venice lagoon water samples gained in different years and different locations. Even if these measurements have been performed with the main goal of testing the suitability of the methods developed, the comparison of the data obtained outline a substantial uniformity of concentration values determined for mercury in the waters of some channels of the town of Venice; these data range between 0.3 and $6 \times 10^{-10} \mathrm{M}$. The majority of these values are slightly higher than the mercury concentration values measured for the coastal water of the Northern Adriatic Sea in the vicinity of Venice $\left((1.6 \pm 0.5) \times 10^{-10} \mathrm{M}[8]\right)$ and in the other neighbouring coastal areas [33-35]. This trend agrees with the increase of mercury concentration expected, when passing from the open sea to coastal and lagoon waters when land based mercury sources (agricultural, industrial or urban) are present in the territory [36,37]. With respect to data published recently for the lagoon of Venice, and obtained by using a prototype electrochemical sensor which works on crude samples [38], our data compare more with the concentrations determined "in situ" with the sensor, rather than with the much higher values determined by the same authors after handling, treating and analysing the samples in the laboratory.

\section{Conclusions}

The combination of an electrochemical preconcentration step at a gold macroelectrode with ICP-MS detection improves the applicability of mercury ICP-MS analysis to complex samples which contain high amounts of salts or other interfering substances. The electrochemical preconcentration step improves the sensitivity of the ICP-MS determination of mercury, however, the not perfect reproducibility of this step (related to its heterogeneous nature) limits its application to determinations of concentrations higher than $10^{-10} \mathrm{M}$.

With respect to previous EC-ICP-MS methods [24], the use of gold electrodes instead of niobium electrodes and the adoption of an electrochemical stripping instead of a chemical reoxidation, allows the shortening of the analysis time from to $2 \mathrm{~h}$ to $20 \mathrm{~min}$.

The EC-ICP-MS method is suitable for determinations of mercury in polluted salt waters and in the control of process streams, in the latter case it gives better analytical performances than DPASV methods.

Attempts to improve the reproducibility of the preconcentration step and to shorten further the analysis time by resorting to flow methods are presently in progress.

\section{Acknowledgements}

Financial support by MURST, Rome (Cofinanziamento 1999-2000 and Piano "Servizi al cittadino ed al territorio", Cluster C 22, Progetto 28) is gratefully acknowledged. We thank Mr. Danilo Rudello (University of Venice) and Mrs. Maristella Zago (EniChem) for skilful technical assistance.

\section{References}

[1] R. Fukay, L. Huynh-Ngoc, Anal. Chim. Acta 83 (1976) 375.

[2] L. Sipos, H.W. Nürnberg, P. Valenta, M. Branica, J. Anal. Chem. Acta 115 (1980) 2.

[3] R.W. Andrews, J.H. Larochelle, D.C. Johnson, Anal. Chem. 48 (1976) 212.

[4] D. Jagner, M. Josefson, K. Åren, Anal. Chim. Acta 141 (1982) 147.

[5] J. Wang, B. Tian, J. Lu, J. Wang, D. Luo, D. MacDonald, Electroanalysis 10 (1998) 399.

[6] R.D. Riso, M. Waeles, P. Monbet, C.J. Chaumery, Anal. Chim. Acta 410 (2000) 97.

[7] G.E. Pinilla, P. Ostapczuk, Anal. Chim. Acta 293 (1994) 55.

[8] P. Ugo, L.M. Moretto, G.A. Mazzocchin, Anal. Chim. Acta 305 (1995) 74.

[9] P. Ugo, L. Sperni, L.M. Moretto, Electroanalysis 15 (1997) 1153.

[10] X. Cai, K. Kalcher, W. Diewald, C. Neuhold, R.J. Magee, Frezenius'Z. Anal. Chem. 345 (1993) 25.

[11] J-M. Zen, M-J. Chung, Anal. Chem. 67 (1995) 3571.

[12] P. Ugo, L.M. Moretto, P. Bertoncello, J. Wang, Electroanalysis 15 (1998) 1017.

[13] J. Labuda, V. Plaskon, Anal. Chim. Acta 228 (1990) 259.

[14] I. Turyan, D. Mandler, Electroanalysis 6 (1994) 838.

[15] P. Ugo, L.M. Moretto, G.A. Mazzocchin, Anal. Chim. Acta 273 (1993) 229.

[16] K. Rajeshwar, J. Ibanez, Enviromental Electrochemistry, Academic Press, San Diego, California, 1997, p. 307.

[17] P.T. Kissinger, W.R. Heineman, Laboratory Techniques in Electroanalytical Chemistry, Marcel Dekker, New York, 1996, p. 734 . 
[18] J.A. Moreton, H. Trevor Delves, J. Anal. Atom. Spectrom. 13 (1998) 659.

[19] A. Woller, H. Garraud, F. Martin, O.F.X. Donard, P. Fodor, J. Anal. Atom. Spectrom. 12 (1997) 53.

[20] C. Shuqin, C. Hangting, Z. Xianjin, J. Anal. Atom. Spectrom. 14 (1999) 1183.

[21] J.R. Pretty, E.A. Blubaugh, J.A. Caruso, T.M. Davidson, Anal. Chem. 66 (1994) 1540.

[22] J.R. Pretty, E.A. Blubaugh, J.A. Caruso, T.M. Davidson, Anal. Chem. 65 (1993) 3396.

[23] I.R. Pretty, E.A. Blubaugh, E.H. Evans, J.A. Caruso, J. Anal. Atom. Spectrom. 7 (1992) 1131.

[24] N-S. Chong, M.L. Norton, J.L. Anderson, Anal. Chem. 62 (1990) 1043.

[25] L. Dunsch, L. Kavan, J. Weber, J. Electroanal. Chem. 280 (1990) 313.

[26] L. Mart, Frezenius' Z Anal. Chem. 296 (1979) 350.
[27] Z. Yoshida, S. Kihara, J. Electroanal. Chem. 86 (1978) 167. [28] T.R. Lindstrom, D.C. Johnson, Anal. Chem. 53 (1981) 1855.

[29] Italian Patent 995,170.

[30] A.E. Martell, R.M. Smith, Critical Stability Constants, Vol. 3, Plenum Press, New York, 1977, p. 314.

[31] R.M. Smith, A.E. Martell, Critical Stability Constants, Vol. 4, Plenum Press, New York, 1976, p. 105.

[32] N.S. Bloom, E.A. Crocelius, Mar. Chem. 14 (1983) 49.

[33] R. Ferrara, B.E. Maserti, Mar. Chem. 38 (1992) 237.

[34] M. Horvat, T. Zvonaric, P. Stengnar, Acta Adriat. 28 (1987) 59.

[35] N. Mikac, Z. Kwokal, K. May, M. Branica, Mar. Chem. 28 (1989) 109.

[36] W. Jackson Davis, Mar. Pol. Bull. 26 (1993) 128.

[37] D. Cossa, J.M. Martin, Mar. Chem. 36 (1991) 291.

[38] S. Daniele, C. Bragato, M.A. Baldo, J. Wang, J. Lu, Analyst 125 (2000) 731. 